\title{
An unsere Leser und Autoren
}

Prof. Dr. Hubert Freiherr von Pechmann hat sich mit Rücksicht auf sein Alter entschlossen, mit Beendigung des 95. Jahrgangs (1976) die Herausgeberschaft des "Forstwissenschaftlichen Centralblattes " in jüngere Hände zu legen. Er bleibt der Zeitschrift dankenswerterweise im Kreise der bei der Herausgabe mitwirkenden Persönlichkeiten auch weiterhin verbunden. An seine Stelle tritt eine Herausgebergemeinschaft. Ihr gehören mit den Herren Prof. Dr. W. KROTH und Prof. Dr. K.-E. ReHfuess, München, Prof. Dr. W. Schöpfer, Freiburg, Prof. Dr. P. Schütt, München, Prof. Dr. B. UlRICH, Göttingen, und Prof. Dr. U. Ammer, München, als federführendem Mitglied, Persönlichkeiten aus allen forstwissenschaftlichen Bildungsstätten der Bundesrepublik Deutschland an. Der Verlag dankt den neuen Herausgebern dafür, $\mathrm{da} ß$ sie sich für diese Aufgabe zur Verfügung gestellt haben und heißt sie herzlich willkommen.

Gleichzeitig wurde der Kreis der bei der Herausgabe mitwirkenden Persönlichkeiten im Sinne der von Prof. AMmER in seinem Geleitwort vorgestellten neuen Konzeption wesentlich erweitert. Neu hinzugetreten sind zu den bisherigen Mitgliedern dieses Gremiums die Herren Ministerialdirigent O. Bauer, München, Prof. Dr. J. FröHLich, Wiesbaden, Prof. Dr. H. Kramer, Göttingen, Prof. Dr. W. Liese, Hamburg, Prof. Dr. H. Mayer, Wien, Prof. Dr. E. Röhrig, Göttingen, Landesforstpräsident Dr. M. Scheifele, Stuttgart, Landesforstmeister Dr. R. Schwarz, Kiel, Prof. Dr. G. Spemdel, Freiburg, Ltd. Ministerialrat O. Zimmer, Saarbrücken, Prof. Dr. H. W. ZöTTı, Freiburg.

Auch ihnen sei für ihre Bereitschaft gedankt, durch ihre Mirwirkung bei der Herausgabe die Entwicklung des „Forstwissenschaftlichen Centralblattes“ zu fördern.

Anläßlich des 70. Geburtstages von Freiherrn von Pechmann am 19. Juli 1975 haben Kollegen, Mitarbeiter und die Verlagsbuchhandlung Paul Parey mit einem Festheft des "Forstwissenschaftlichen Centralblattes" seine wissenschaftlichen Leistungen und seine persönlichen Verdienste um unsere Zeitschrift in Verehrung und Dankbarkeit gewürdigt. Dies heute erneut zu bekräftigen, ist uns ein herzliches Bedürfnis. Damit sei der Wunsch verbunden, auch in Zukunft des reichen Wissens und der großen Erfahrung des Mannes teilhaftig zu bleiben, der in über 28jähriger Arbeit als Herausgeber das "Forstwissenschaftliche Centralblatt" nach dem Kriege aufgebaut und ihm den Rang geschaffen hat, der es seinen Nachfolgern in dieser Aufgabe möglich macht, auf diesem gesicherten Fundament weiterzubauen.

Die Zukunft stellt uns vor neue Aufgaben. Für ihre Bewältigung wünscht der Verlag dem neuen Herausgeberkreis einen guten Geist und die Kraft, neue Ideen zu verwirklichen - und ein wenig Glüdk. Dann werden Erfolg und Befriedigung für diese Mühen im Dienste der Forstwissenschaft und ihre Wirkung in die Praxis nicht ausbleiben. 